\title{
Análise dos determinantes da utilização de assistência técnica por agricultores familiares do Brasil em 2014
}

\author{
Determinants of the use of technical assistance by \\ Brazilian family famers in 2014
}

Adauto Brasilino Rocha Junior ${ }^{1}$ (D), Jacy Alves de Freitas $^{2}$ (D), Francisco Carlos da Cunha Cassuce ${ }^{2}$ (D) e Silvia Maria Almeida Lima Costa ${ }^{3}$

Resumo: No presente trabalho são analisados os determinantes da utilização de assistência técnica pelos agricultores familiares brasileiros em 2014. Utilizando dados da Pesquisa Nacional por Amostras Domiciliares (PNAD) de 2014, foi estimado um modelo de regressão qualitativa probit, permitindoa identificação da magnitude e significância do efeito de cada variável explicativa sobre a probabilidade de utilização de assistência técnica no último trabalho agrícola desenvolvido no empreendimento. Os resultados evidenciam que o perfil socioeconômico, as características produtivas e a localização do agricultor familiar afetam significativamente a probabilidade de utilização da assistência técnica. Observou-se que o fato de um indivíduo possuir pele não branca, ter como principal canal de comercialização a venda direta ao consumidor, ser cessionário ou apresentar condição não especificada em relação à terra, possuir idade avançada ou baixa escolaridade ou renda per capita apresentam efeito estatisticamente significativo de redução na probabilidade de utilização da assistência técnica. Por outro lado, o fato de o indivíduo ter como principal canal de comercialização a venda para empresas ou cooperativas, de possuir empregados temporários ou estar localizado na região Sul aumentam essa probabilidade. Conclui-se, por fim, que estudos aprofundados para o melhor entendimento desses efeitos podem fornecer respaldo para o aperfeiçoamento das ações de assistência técnica.

Palavras-chaves: ater, agricultura familiar, assistência técnica, capacitação técnica.

Data de submissão: 24 de agosto de 2017. Data de aceite: 22 de abril de 2018.

1. Escola Superior de Agricultura "Luiz de Queiroz", Universidade de São Paulo (USP), Piracicaba (SP), Brasil. E-mail: adauto.junior.20102@gmail.com

2. Universidade Federal de Viçosa (UFV), Viçosa (MG), Brasil. E-mail: jacyalves29@gmail.com; francisco.cassuce@ufv.br

3. Universidade Estadual Paulista "Júlio de Mesquita Filho" (UNESP), Ilha Solteira (SP), Brasil. E-mail: smalcost@agr.feis.unesp.br 


\begin{abstract}
This paper analyzes the determinants of the use of technical assistance by Brazilian family farmers in 2014 . Using data from the National Survey by Household Samples (PNAD) of 2014, a qualitative probit regression model was estimated, allowing the identification of the magnitude and significance of the effect of each explanatory variable on the probability of using technical assistance in the last agricultural work developed in the enterprise. The results show that the socioeconomic profile, the productive characteristics and the location of the family farmer affect significantly the probability of using technical assistance. It was observed that the fact that an individual with non-white skin, who has as main marketing channel direct sale to the consumer, be transferee or present unspecified condition in relation to the land, has advanced age or low education or income per capita has a statistically significant effect of reducing the probability of using technical assistance. On the other hand, the fact that the individual has as a main marketing channel the sale to companies or cooperatives, has temporary employees or he/she is located in the south region increases this probability. It is concluded, finally, that in-depth studies to better understand these effects can provide support for the improvement of technical assistance actions.
\end{abstract}

Key-words: ater, family farming, technical assistance, technical capacitation.

Classificação JEL: C01, C21, C25.

\section{Introdução}

O agronegócio é o setor com maior participação no PIB brasileiro, sendo responsável por mais de R\$1,47 trilhão em 2016 (Centro de Estudos Avançados em Economia Aplicada, 2016). A agricultura familiar constitui um dos principais segmentos desse setor ao lado da agroindústria, respondendo por aproximadamente $38 \%$ da produção agrícola nacional, contribuindo, principalmente, com o fornecimento de produtos básicos da cesta de alimentos brasileira, como arroz, feijão, milho e carnes (Castro, 2015).

Essa relevância da produção agrícola familiar pode ser observada em termos de representatividade no Produto Interno Bruto brasileiro, pois o segmento foi responsável por $9 \%$ do PIB do País em 2005 (Guilhoto et al., 2007), e é ainda mais evidente quando são analisados os resultados do último Censo Agropecuário, nos quais identificou-se que a agricultura familiar gerou 33,92\% das receitas agrícolas de 2006, utilizando apenas 24,32\% da área cultivada (Instituto Brasileiro de Geografia e Estatística, 2009), dados que também evidenciam uma capacidade produtiva considerável.

Outros aspectos dessa atividade são a alta capacidade de absorção de mão de obra e a descentralização da posse da terra. Segundo os dados do Censo Agropecuário de 2006, a base de dados agrícolas disponíveis mais recentes em termos nacionais, $84,40 \%$ dos empreendimentos rurais brasileiros são classificados como propriedades agrícolas familiares e utilizam menos de um quarto da área brasileira cultivada, como já citado, ocupando 74,38\% da mão de obra total utilizada na agricultura (Instituto Brasileiro de Geografia e Estatística, 2009).
No entanto, embora apresente potencial econômico e social considerável, a agricultura familiar enfrenta dificuldades próprias, características de uma atividade que é, segundo (Batalha et al., 2005), exercida por produtores pouco qualificados e inseridos em um ambiente altamente competitivo e tecnificado como o da agricultura brasileira. Segundo Abramovay (1998), algumas restrições ao desenvolvimento da agricultura familiar no Brasil são a dificuldade na construção de capital social e na inserção nos mercados, fatores que impedem que os agricultores familiares valorizem os atributos de sua localização, construam mercados e transformem, ao seu favor, o ambiente institucional no qual estão inseridos. Um instrumento para o fortalecimento da atividade seria, nesse caso, a oferta de assistência técnica e extensão rural.

No Brasil, grande incentivo foi dado à criação de instituições de pesquisa agropecuária e à formação de especialistas em áreas do conhecimento privilegiadas para a inovação no campo. Essas áreas incluem especialistas em máquinas agrícolas, biologia e química dos solos, irrigação e drenagem do solo, melhoramento genético animal e vegetal, desenvolvimento de novos fertilizantes e defensivos agrícolas, entre outros. Com a finalidade de difundir essas inovações no meio rural, existe a Assistência Técnica e Extensão Rural (Ater), realizada por profissionais capacitados para promover este conhecimento no ramo agropecuário (Castro, 2015). Abramovay (1998) deixa clara a importância da Ater, indicando que esta não se limitaria apenas às tarefas agrícolas estritamente produtivas, mas também possuiria 
em seu escopo o objetivo de proporcionar cidadania, desenvolvimento sustentável e a ampliação do acesso ao conhecimento e ao mercado.

Nesse contexto da importância econômica e social da agricultura familiar no Brasil, e da relevância da Ater enquanto serviço estratégico para o desenvolvimento dessa categoria de produtores, o presente trabalho consiste em uma análise dos determinantes da utilização do serviço de assistência técnica por agricultores familiares brasileiros em 2014. Utilizando-se dados da Pesquisa Nacional por Amostras Domiciliares (PNAD) de 2014 são realizadas análises estatística descritiva e econométrica por meio da estimação de um modelo Probit (Instituto Brasileiro de Geografia e Estatística, 2014). Avalia-se, desse modo, a hipótese de que as características geográficas, socioeconômicas e produtivas, que caracterizam o perfil do produtor familiar, apresentam efeito significativo sobre a probabilidade de utilização de assistência técnica por esse público.

\section{Agricultura familiar e assistência técnica no Brasil}

O termo agricultura familiar se popularizou no Brasil, de acordo com Wanderley (2013), depois da implantação do Programa Nacional de Fortalecimento da Agricultura Familiar (Pronaf) em 1995, cujo objetivo principal foi o de fomentar o desenvolvimento sustentável da agricultura familiar. Nas resoluções da Lei n. 11.326/2006 e nas atualizações dadas pelo Decreto n. 9.064/ 2017, agricultor familiar é o empreendedor familiar rural que pratica atividades no meio rural, possui área de até quatro módulos fiscais, mão de obra predominantemente familiar e renda e gerenciamento do empreendimento vinculados à própria família (Brasil, 2006, 2017). No entanto, a abrangência do conceito é comumente discutida entre legisladores e especialistas. Enquanto para alguns se confunde com a definição operacional adotada pelo Pronaf para definir os beneficiários do programa, para outros, a categoria corresponde à uma camada de agricultores capaz de se adequar às exigências modernas do mercado, opondo-se à ideia de pequenos produtores, que seriam incapazes de assimilar essas inovações (Wanderley, 2013).

Castro (2015) afirma que, apesar da importância histórica, a classe dos agricultores familiares recebeu, ao longo do tempo, pouca atenção do poder público, sendo por várias vezes negligenciada. Adicionalmente, Guilhoto et al. (2007) presumem que a sobrevivência deste setor produtivo se torna incerta na medida em que o ramo é desorganizado e ineficaz para que possa gerir seus próprios interesses. A dificuldade de gestão normalmente está associada à diversidade de sistemas e estratégias produtivas que determinam objetivos distintos, fazendo com que a força do setor seja dissipada em grupamentos locais (Guilhoto et al., 2007). Buainain et al. (2003) mencionam que o produtor familiar, quando recebe apoio suficiente, é capaz de produzir uma renda total, incluindo a de autoconsumo, superior ao custo de oportunidade do trabalho, o que viabilizaria a atividade.

Segundo Batalha et al. (2005), há um consenso entre formuladores e gestores de políticas públicas de que a competitividade da agricultura familiar só pode ser alcançada por meio da adoção de práticas que estimulem a cooperação entre os agentes econômicos da cadeia produtiva, incluindo o governo. Ademais, o autor afirma que uma das maneiras de fortalecer a agricultura familiar é por meio da agregação de valor aos seus produtos. Essa ideia realça a importância de ações de capacitação como a assistência técnica e a extensão rural (Ater), que devem não apenas abordar os aspectos técnicos da atividade, mas também tratar das características gerenciais.

A origem dos serviços de Ater no Brasil se situa em 1948, quando foi criada a Associação de Crédito e Assistência Rural (Acar) no estado de Minas Gerais, sob recomendação do empresário norte-americano Nelson Rockfeller (Castro, 2015). Conforme Castro (2015), a Acar foi estruturada de acordo com o modelo norte-americano de difusão de inovações, que basicamente atribuía à extensão rural a missão de oferecer assistência técnica e financeira aos produtores rurais para que adotassem as inovações desenvolvidas em institutos de pesquisa agrícola.

Segundo Oliveira (1999), ao final da década de 1950, os serviços de Ater estavam presentes na metade dos estados brasileiros, abrangendo completamente as regiões Sudeste e Sul, e expandindo-se para os estados do Nordeste (CE, PE, BA, RN, PB) e Centro-Oeste (GO). Caporal (1998) ressalta que, em 1956, a Associação Brasileira de Crédito e Assistência Rural (Abcar) entidade de caráter privado -, congregou todas as Acars segundo um modelo centralizado e vertical de orientação. 
Entretanto, com o crescimento dessas instituições, o Estado brasileiro gradativamente foi trazendo-as para sua esfera de influência e controle, oferecendo apoio financeiro e exigindo em troca apoio ao seu projeto de desenvolvimento rural, culminando em 1975 com a criação da Empresa Brasileira de Assistência Técnica e Extensão Rural (Embrater), que incorporou a Abcar, e trocou o nome das unidades estaduais de Acar por empresa estadual de assistência técnica e extensão rural (Emater), as quais ficaram subordinadas ao seu controle (Castro, 2015).

É importante ressaltar que, apesar da extensão das ações dos órgãos de Emater estaduais, existem outras entidades que oferecem o serviço de assistência aos produtores familiares, como algumas agências municipais, estaduais e federais (por exemplo, as secretarias municipais de agricultura), e até mesmo empresas privadas, como algumas empresas compradoras da produção para beneficiamento, ou vendedoras de insumos, as quais disponibilizam técnicos para atender os agricultores no campo.

O último Censo Agropecuário realizado em 2006 pelo Instituto Brasileiro de Geografia e Estatística (IBGE) trouxe informações relevantes sobre a abrangência da orientação técnica aos produtores. Um resultado observado na pesquisa foi que a orientação técnica é utilizada em $22 \%$ dos estabelecimentos rurais, os quais ocupam quase metade das terras utilizadas na agricultura. Além disso, a área média dos agricultores assistidos é de 228 ha, enquanto a dos não assistidos é de 42 ha. Tais números evidenciam uma clara segmentação da assistência técnica em função de sua origem e do tamanho das propriedades assistidas (Instituto Brasileiro de Geografia e Estatística, 2009).

Ainda segundo os dados do Censo Agropecuário de 2006, a assistência técnica originária do governo atingiu $43 \%$ dos estabelecimentos e está mais voltada para os estabelecimentos menores, com área média de 64 ha. Já a assistência de empresas privadas de planejamento atendeu as propriedades com área média de 506 ha (Instituto Brasileiro de Geografia e Estatística, 2009). O Censo também mostrou que o nível de escolaridade da pessoa responsável pela propriedade tem forte relação com o recebimento da assistência técnica. Dos produtores com instrução igual ou inferior ao Ensino Fundamental incompleto, apenas 16,8\% receberam assistência técnica; para os produtores com Ensino Fundamental completo este percentual sobe para $31,7 \%$; e para os produtores com nível superior, excetuando-se aqueles com formação em ciências agrárias e veterinária, a assistência técnica alcança 44,7\% dos estabelecimentos (Instituto Brasileiro de Geografia e Estatística, 2009). Esse resultado é preocupante, pois apenas $19,6 \%$ dos produtores entrevistados no censo têm Ensino Fundamental completo ou mais.

Os fatores regionais também apresentaram diferenças quando se trata de utilização de assistência técnica. Quirino et al. (2002) mostraram que o percentual de propriedades atendidas é de $50,5 \%$ das unidades produtivas no Sul, $41,5 \%$ no Sudeste, 32\% no Centro-Oeste, $14,6 \%$ no Nordeste e de $14,5 \%$ no Norte.

Apesar da importância desses resultados, não existem análises específicas dos fatores que determinam a utilização da assistência técnica por agricultores familiares em termos nacionais, e a principal fonte de dados para esse tipo de estudo, que é o Censo Agropecuário, não é atualizada desde 2006. Por esse motivo, considerando-se a falta de estudos com dados mais recentes sobre o tema, entende-se que o presente trabalho propicia uma relevante contribuição não apenas à literatura sobre assistência técnica aos agricultores familiares brasileiros, mas também ao aperfeiçoamento da política de Ater no território nacional.

\section{Metodologia}

\subsection{Escolha e aplicação do modelo de regressão probit}

Considerando que o objetivo do estudo é avaliar como as características que definem diferentes perfis de agricultores familiares afetam a probabilidade de receberem assistência técnica, optou-se pela utilização de um modelo de regressão qualitativa probit. A escolha desse modelo justifica-se pelo fato de que a sua estimação permite avaliar a magnitude e a significância do efeito de cada variável explicativa sobre a probabilidade de recebimento de assistência técnica, controlando-se o efeito das demais variáveis incluídas no modelo.

A opção pelo modelo probit orienta-se pela melhor adequação dessa forma funcional ao problema de pesquisa. Segundo Gujarati \& Porter (2011), por razões históricas e práticas, as funções de distribuição amostral utilizadas nos modelos de probabilidade são a logística 
e a normal, a primeira dando origem ao modelo logit, e a segunda, ao modelo probit (normit). Ainda segundo os autores, na maioria das aplicações os modelos são bastante parecidos, não existindo razões convincentes para a escolha entre um ou outro, sendo que, na prática, o modelo logit é o mais utilizado devido à sua relativa simplicidade matemática.

Apesar da semelhança entre o logit e o probit, a escolha do probit para o presente estudo não foi realizada de forma arbitrária. A comparação entre os testes de ajustamento dos dois modelos para os dados analisados evidenciou um ajustamento ligeiramente melhor para o probit ${ }^{1}$. Segundo Gujarati \& Porter (2011), no modelo probit pressupõe-se a existência de uma variável latente $I_{i}$, que, no contexto do presente estudo, pode ser interpretada como um índice de utilidade não observável da assistência técnica. Considera-se que $I_{i}$ é uma função linear das variáveis explicativas, de modo que, quanto maior o valor de $I_{i}$, maior a probabilidade de o agricultor utilizar a assistência técnica. No presente estudo, o índice $I_{i}$ é expresso pela Função (1).

$I_{i}=\beta_{I}+\beta_{2} I d_{i}+\beta_{3} R_{i}+\beta_{4} E_{i}+\beta_{5} F_{i}+\beta_{6} n b_{i}+$

$\beta_{7}$ Etemp $_{i}+\beta_{8}$ Eperm $_{i}+V_{1}$ Cond $_{i}+V_{2} P_{i}+V_{3}$ Rg $_{i}+V_{4} C_{i}$

em que $I_{i}$ é o índice de utilidade da assistência técnica para o $i$-ésimo agricultor; $\beta_{1}$ é o intercepto; $\beta_{2,} \beta_{3,} \beta_{4}, \beta_{5}, \beta_{6}$, $\beta_{7}, \beta_{8}$, são os parâmetros associados às suas respectivas variáveis, em que $I d_{i}$ é a variável contínua anos de idade; $\mathrm{R}_{\mathrm{i}}$ representa renda per capita dos agricultores; $\mathrm{E}_{\mathrm{i}}$ indicaria, de forma contínua, os anos de escolaridade dos pequenos produtores; $\mathrm{F}_{i}$ é uma variável dummy para gênero feminino; $\mathrm{nb}_{\mathrm{i}}$ é a variável dummy para cor de pele não branca; Etemp $p_{i}$ é a dummy que indica a participação de empregados temporários no trabalho, e Eperm é a dummy que indica a participação de empregados permanentes no trabalho. $V_{1}, V_{2}, V_{3}$, e $V_{4}$, são os vetores de parâmetros associados aos seus respectivos vetores de variáveis dummy, em que Condi é um vetor com cinco dummies que indicam condição do indivíduo em relação

\footnotetext{
Como teste de ajustamento utilizou-se o valor da área sob a curva Roc para cada modelo estimado, e o pseudo $\mathrm{R}^{2}$ de McFadden. A área sob a curva ROC para o modelo probit $(0,8257)$ foi um pouco maior que o do logit $(0,8249)$, indicando um ajustamento ligeiramente melhor do primeiro em relação ao segundo. $\mathrm{O}$ valor do pseudo $\mathrm{R}^{2}$ de McFadden para o probit foi de 0,2318 , também ligeiramente maior que o do logit, que foi de 0,2312 , comprovando, desse modo, o melhor ajuste do modelo probit à análise dos dados em questão.
}

ao empreendimento (parceiro, arrendatário, posseiro, cessionário ou outra condição), Pi é um vetor com duas dummies que indicam a finalidade da produção (produção apenas para subsistência, produção exclusivamente comercial), $\mathrm{Rg}_{\mathrm{i}}$ é um vetor com quatro dummies que indicam a região do País em que a propriedade está localizada (Norte, Nordeste, Centro-Oeste, ou Sudeste), e $C_{i}$ é um vetor com dummies que indicam o principal comprador da produção (cooperativa, empresa, intermediário, venda para o proprietário do empreendimento, diretamente ao consumidor ou outro comprador). Cada variável dummy recebe valor 0 ou 1 , sendo que o valor 1 indica que a característica representada pela variável está presente na observação, e o 0 indica que a característica está ausente.

Visando evitar o problema de colinearidade perfeita devido ao uso de dummies para todas as categorias possíveis, por convenção, foram utilizadas como características de referência aquelas que apresentam maior percentual de agricultores que recebem assistência técnica. Assim, foram definidas como características base a cor da pele branca, gênero masculino, a inexistência de empregados temporários ou permanentes, a condição de proprietário, o governo como principal comprador, a produção destinada tanto ao consumo quanto ao comércio, e a localização na região Sul.

A relação da variável latente $I_{i}$ com a probabilidade de o indivíduo utilizar a assistência técnica pode ser estabelecida considerando-se que existe um nível crítico ou limiar do índice, que pode ser chamado de $I_{i}{ }^{*}$, tal que, se $I_{i}$ exceder $I_{i}{ }^{*}$, o agricultor utiliza a assistência técnica, caso contrário, não. Segundo Gujarati \& Porter (2011), embora $I_{i}^{*}$ também não seja observável, supondo-se que ele se distribui normalmente com a mesma média e variância, é possível estimar os parâmetros e obter algumas informações sobre o próprio índice. Dada a hipótese da normalidade, a probabilidade de que $I_{i}^{*}$ seja menor ou igual a $I_{i}$ pode ser calculada por meio da FDA normal padronizada como:

$$
\begin{aligned}
& P_{i}=P(Y=I \mid X)=P\left(I_{i}^{*} \leq I_{i}\right)=P\left(Z_{i} \leq I_{i}\right)= \\
& F\left(\begin{array}{l}
\beta_{1}+\beta_{2} I+\beta_{3} R+\beta_{4} E+\beta_{5} F+\beta_{6} n b+\beta_{7} \text { Etemp }+ \\
\beta_{8} \text { Eperm }+V_{1} \text { Cond }+V_{2} P+V_{3} R g+V_{4} C
\end{array}\right)
\end{aligned}
$$

em que $P(Y=1 \mid X)$ indica a probabilidade de utilizaçãoa assistência técnica dados os valores das variáveis explicativas, e em que $Z_{i}$ é a variável normal padrão, com $Z \sim N\left(0, \sigma^{2}\right)$. $F$ é a FDA normal padrão, escrita explicitamente na forma: 
$F\left(I_{i}\right)=\frac{1}{\sqrt{2 \pi}} \int_{-\infty}^{I_{i}} e^{-z^{2} / 2} d z$

Por fim, a obtenção da probabilidade da utilização da assistência técnica para determinado produtor é dada pela área da curva normal padrão de $-\infty$ à $I_{i}$. Segundo Gujarati \& Porter (2011), para se ter informações sobre $I_{i}$, assim como sobre os parâmetros da Função 1, utiliza-se o inverso da Equação 2, obtendo-se:

$I_{i}=F^{-1}\left(I_{i}\right)=F^{-1}\left(P_{i}\right)=\beta_{1}+\beta_{2} I+\beta_{3} R+$

$\beta_{4} E+\beta_{5} F+\beta_{6} n b+\beta_{7}$ Etemp $+\beta_{8}$ Eperm +

$V_{1}$ Cond $+V_{2} P+V_{3} R g+V_{4} C$

Com base nessas informações, os parâmetros são estimados por máxima verossimilhança. Considerando que as variáveis explicativas caracterizam o perfil do agricultor familiar, entende-se que elas podem estar associadas à probabilidade de o produtor ter acesso ou de solicitar o serviço de assistência técnica, o que deve ser evidenciado pela significância dos parâmetros estimados. Nesse caso, existindo efeitos significativos das características do agricultor familiar, é fundamental compreendê-los para o aperfeiçoamento dos serviços de assistência técnica.

\subsection{Fonte, preparação dos dados e estimação}

Devido à relevância dos programas de fomento produtivo a nível nacional, a Pesquisa Nacional por Amostras Domiciliares (PNAD) realizou, em 2014, o levantamento de dados sobre Acesso à Internet e à Televisão e Inclusão Produtiva, na forma de uma pesquisa suplementar. Esses dados sobre inclusão produtiva incluem perguntas sobre a área dos empreendimentos, se foi recebida assistência técnica no último trabalho realizado na propriedade, se houve utilização de crédito rural, se o crédito utilizado foi acessado por meio do Pronaf, entre outras questões referentes a fomento produtivo recebido por produtores rurais.

A PNAD é uma importante fonte de dados para pesquisas econômicas no Brasil, dada sua abrangência e também diversidade de variáveis pesquisadas. Por esse motivo, o presente trabalho baseia-se na utilização dos dados da pesquisa básica e da pesquisa suplementar da PNAD de 2014. Com base nos dados de recebimento de assistência técnica, e com outras variáveis que caracterizam o perfil do agricultor e potencialmente podem explicar esse fenômeno, foram definidos os dados relativos à variável dependente e às variáveis explicativas utilizadas no modelo probit, os quais são apresentados no Quadro 1.

Ressalta-se que outras variáveis explicativas foram testadas, como a área do empreendimento. No entanto, essas variáveis geraram problemas de estimação, como a redução substancial do número de observações (diminuindo a significância dos parâmetros estimados), e o prejuízo do ajustamento do modelo. Foi considerando esses aspectos que se recorreu à eliminação destas variáveis no modelo.

Quadro 1. Dados utilizadas no modelo

\begin{tabular}{|c|c|}
\hline Variável Dependente & Variáveis explicativas \\
\hline \multirow{11}{*}{ Recebeu assistência técnica no último ano } & Idade \\
\hline & Renda per capita \\
\hline & Escolaridade \\
\hline & Gênero (masculino ou feminino) \\
\hline & Cor da pele (branco ou não branco) \\
\hline & $\begin{array}{l}\text { Condição em relação à propriedade (proprietário, posseiro, } \\
\text { cessionário, arrendatário, parceiro ou outra condição) }\end{array}$ \\
\hline & $\begin{array}{l}\text { Finalidade da produção (apenas para consumo de subsistência, } \\
\text { exclusivamente comercial, ou consome parte da produção) }\end{array}$ \\
\hline & Participação de um ou mais empregados temporários \\
\hline & Participação de um ou mais empregados permanentes \\
\hline & Região do país (Norte, Nordeste, Centro-Oeste, Sudeste, Sul) \\
\hline & $\begin{array}{l}\text { Principal comprador da produção (venda direta para consumidor, } \\
\text { para empresa, cooperativa, intermediário, governo, para o } \\
\text { proprietário da terra, ou para outro comprador) }\end{array}$ \\
\hline
\end{tabular}

Fonte: Elaboração própria. 
Outro aspecto importante é que os dados da PNAD são oriundos de um processo de amostragem complexa, que abrange todo o território nacional. Esse tipo de amostragem caracteriza-se pela não aleatoriedade na escolha das observações e, por esse motivo, exige procedimentos específicos de preparação de dados, para que os estimadores obtidos a partir de sua análise não sejam enviesados. Esse procedimento é conhecido como setagem, e foi realizado na preparação dos dados para a estimativa do modelo utilizado.

Pelo fato de não existir na PNAD uma classificação que permita a identificação direta dos agricultores familiares (um perfil específico de produtor rural), torna-se necessário realizar o truncamento da amostra, excluindo-se da análise as observações referentes a domicílios e pessoas que não se enquadrariam nos requisitos que definem o perfil dos agricultores familiares. Para esse recorte utilizou-se como referência a Lei n. 11.326, de 24 de julho de 2006, que estabelece as diretrizes para a formulação da política nacional da agricultura familiar e empreendimentos familiares rurais; e também a renda máxima estabelecida como um dos requisitos para o acesso ao Programa Nacional de Fortalecimento da Agricultura Familiar (Pronaf)2. Por esse motivo, foram excluídas da amostra utilizada no presente trabalho as observações:

- Que se enquadram nas situações censitárias urbana (cidade ou vila, área urbanizada) ou urbana (área urbana isolada): entende-se que as observações que se enquadravam nessas categorias não incluem agricultores, os quais pertencem às categorias de situação censitária rural, ou à subcategoria urbana (cidade ou vila, área não urbanizada);

- Aquelas referentes às pessoas que não são consideradas de referência de seus domicílios: considera-se que a pessoa de referência do domicílio é a responsável pelas decisões do empreendimento, e sintetiza as principais características da família;

\footnotetext{
2 Embora a Lei n. 11.326, de 24 de julho de 2006 (Brasil, 2006), estabeleça os critérios legais que definem a categoria dos agricultores familiares, o único critério legal objetivo que permite recorte da amostra é a área do empreendimento. No entanto, na PNAD há poucas amostras nas quais a área do empreendimento foi informada. Portanto, visando delimitar da melhor maneira possível a amostra utilizada no presente trabalho, minimizando-se as perdas devido à falta de informação, no truncamento utilizou-se também o critério de renda máxima para acesso ao Pronaf, pois ele é considerado o principal programa de fomento à agricultura familiar.
}

- Aquelas referentes aos empreendimentos com área maior que 480 hectares: a Lei n. 11.326 , de 24 de julho de 2006, define, como uma das características do agricultor familiar, que o empreendimento deveria possuir área de até quatro módulos fiscais. No entanto, o módulo fiscal é uma unidade de medida agrária instituída pela Lei n. 6.746, de 10 de dezembro de 1979, que representa a área mínima necessária para as propriedades rurais serem consideradas economicamente viáveis (Landau et al., 2012). Essa área varia conforme o município, podendo medir de 5 a 120 hectares. Devido à dificuldade em realizar a exclusão das observações referentes aos empreendimentos com área maior que quatro módulos fiscais para cada município, considerando que a menor unidade territorial de agregação que a PNAD permite é a nível de estados ou regiões metropolitanas, foi realizada a dropagem (exclusão) das observações para as quais a área do empreendimento é maior do que 480 hectares, o que permitiu a eliminação de alguns outlayers. É importante destacar, no entanto, que, na análise estatística descritiva das áreas do empreendimento informadas na amostra, verificou-se que $98,92 \%$ das áreas informadas têm 19,36 hectares ou menos, obedecendo ao requisito de acesso quando o módulo fiscal é o menor possível (cinco hectares). Conclui-se, portanto, que considerando a estrutura fundiária verificada na amostra, na qual predominam as pequenas propriedades com tamanho abaixo de quatro módulos fiscais (em seu valor mínimo verificado no Brasil), o prejuízo decorrente da impossibilidade de truncar a amostra perfeitamente com relação ao critério área é praticamente irrelevante.

- Aquelas referentes aos empreendimentos com renda mensal domiciliar maior do que $\mathrm{R} \$ 30.000,00$ : um dos requisitos de acesso ao Pronaf é que a renda bruta familiar nos últimos 12 meses de produção normal, que antecedem a solicitação da declaração de aptidão ao Pronaf (DAP), deve ser de até $\mathrm{R} \$ 360.000,00$ (trezentos e sessenta mil reais), considerando neste limite a soma de $100 \%$ (cem por cento) do Valor Bruto de Produção (VBP), 100\% do valor da receita recebida de entidade integradora e das demais rendas provenientes de atividades desenvolvidas no estabelecimento e fora dele, recebida por qualquer componente familiar, excluídos os 
benefícios sociais e os proventos previdenciários decorrentes de atividades rurais (Portal Atividade Rural, 2013). Portanto, pelo fato de a renda mensal domiciliar declarada na PNAD não incluir os benefícios sociais e os proventos previdenciários decorrentes de atividades rurais, considera-se que a dropagem dos domicílios com renda mensal maior que $\mathrm{R} \$ 30.000,00$ permite a delimitação da amostra segundo esse critério.

Deve-se ressaltar que, apesar de a preparação dos dados ser realizada com o objetivo de delimitar a amostra para a população mais próxima o possível daquela definida como agricultores familiares no presente trabalho, existem limitações decorrentes de aspectos da base de dados. A principal limitação encontrada é o pouco número de observações em que foi informada a área do empreendimento. Isso é compreensível devido à dificuldade dos agricultores em informar a área de seu empreendimento no exato momento da coleta de dados.

Porém, considerando-se a relevância do tema e a rica disponibilidade de outras variáveis explicativas, entende-se que a existência de algumas limitações não inviabiliza a análise. Ao invés disso, o desafio de trabalhar com as informações existentes, minimizando a perda resultante das deficiências da base de dados, e extraindo o máximo possível de informações úteis, torna-se mais uma motivação para o presente estudo.

Após a setagem e o truncamento da amostra, pode-se estimar o modelo probit. As análises da significância e do ajustamento do modelo foram realizadas por meio dos testes de Wald e da Curva de ROC (Receiver Operating Characteristic). O teste de Wald é um teste de significância global que consiste na comparação entre dois modelos, o modelo irrestrito (com todas as variáveis e os parâmetros estimados), e o modelo restrito, que obedece alguma especificação (para o presente trabalho é que os parâmetros são todos iguais a zero). Desse modo, avalia-se a hipótese nula de que os coeficientes são todos iguais a zero, cuja rejeição significa a aceitação da hipótese alternativa de que a regressão é estatisticamente significativa.

A utilização da Curva de ROC, por sua vez, objetiva avaliar o ajustamento do modelo. O princípio desta curva é representar graficamente a relação entre os verdadeiros positivos (sensitividade) e os falsos alarmes ou positivos (especificidade) (Braga, 2000; Cameron \& Trivedi, 2010; Fávero \& Belfiore, 2014). O gráfico da Curva ROC de um modelo representa os pares de probabilidades estimadas dos verdadeiros positivos (sensitividade, representada no eixo vertical) e dos falsos positivos (dada pela diferença "1 - especificidade", representada no eixo horizontal).

A análise do ajustamento do modelo com a Curva de ROC baseia-se na utilização da área sob a curva, que serve como um indicador de ajustamento. Quanto mais próximo de 1 for o valor da área, ou seja, quanto mais próxima a curva estiver do canto esquerdo superior, melhor a precisão do modelo em discriminar o evento de interesse dos falsos alarmes (Braga, 2000; Cameron \& Trivedi, 2010; Fávero \& Belfiore, 2014), o que indica um melhor ajustamento da estimação ao problema de pesquisa.

Com o modelo estimado, e comprovados a sua significância estatística e o seu ajustamento satisfatório, é possível discutir o efeito das diferentes variáveis explicativas incluídas no modelo, sobre a probabilidade da utilização da assistência técnica. No tópico seguinte, estrutura-se a discussão dos resultados em dois tópicos. No primeiro realiza-se uma breve análise estatística descritiva de algumas variáveis e, no segundo, são discutidos os resultados do modelo econométrico estimado. Esses dados permitem visualizar o quanto esse serviço de fomento produtivo atinge seu público-alvo, evidenciando a possível necessidade de aperfeiçoamento das ações de capacitação, ou mesmo de intervenções direcionadas a públicos específicos.

\section{Resultados e discussão}

Com o objetivo de melhor explorar os dados disponíveis na PNAD 2014, este tópico é dividido em duas partes. Na primeira, apresenta-se a análise estatística descritiva dos dados. Na segunda, são apresentados os resultados do modelo estimado.

\subsection{Estatística descritiva}

A análise descritiva de dados teve como objetivo contextualizar a problematização estudada, permitindo a identificação da proporção de agricultores familiares que receberam assistência técnica no ano anterior ao da pesquisa, de acordo com a fonte de assistência, a região do País, a posição em relação ao empreendimento e o principal comprador da produção. O Quadro 2 mostra 
a participação percentual de cada fonte de assistência com relação ao total de agricultores familiares assistidos.

Observa-se, no Quadro 2, que o governo foi o principal provedor de Ater para os agricultores familiares do País em 2014, respondendo pela assistência a 55,82\% desse público. Esse resultado evidencia a importância da atuação das agências estaduais da Emater no País (e outras correligionárias, como no caso do estado de São Paulo), ao menos com relação à abrangência do atendimento, e também é um indício do poder de atuação do governo sobre a agricultura familiar brasileira. De acordo com Teixeira (2002), a lei de política agrícola descentraliza a execução dos serviços de apoio ao setor rural, porém, centraliza a elaboração da política de desenvolvimento rural para o estado, em que prevê ações de planejamento, crédito, mecanização e infraestrutura para os produtores.

É importante considerar que, a partir dos anos 2000, a Política Nacional de Assistência Técnica e Extensão rural (Pnater) foi alicerçada em novas estratégias de descentralização dos serviços, em especial para agricultores familiares beneficiários de projetos de reforma agrária (Brasil, 2004, 2008). A descentralização preconizada pela nova política tem contemplado maior envolvimento de atores locais, em geral reunidos em arranjos cooperativos e selecionados pelo Estado através de editais públicos para a execução dos serviços de extensão rural, com contratos para atendimento a demandas específicas e por período determinado. Disto decorre que a presença do Estado pode ter importância efetiva mais expressiva do que o registrado (quase $56 \%$ de participação) porquanto efetivamente atuou como supervisor dos projetos de extensão rural contratados.

Desse modo, esta participação estatal é reveladora de que, embora tenha havido significativo afastamento do Estado no fornecimento de assistência técnica para a agropecuária, em geral na década de 1990, como atestaram Rivera \& Cary (1997) e Peixoto (2009), para o segmento da agricultura familiar a atuação estatal continua sendo o principal meio de condução de tecnologia e assistência técnica.

Em sintonia com o maior protagonismo das empresas privadas no fornecimento de assistência técnica vinculada à comercialização de insumos para os complexos produtivos, a agricultura familiar também foi beneficiária das estratégias de atuação do setor privado, que respondeu por $40,32 \%$ da assistência aos agricultores familiares brasileiros em 2014. No Quadro 3 são apresentados os percentuais de agricultores familiares assistidos no último ano em cada região do Brasil.

A região que teve o maior percentual de agricultores familiares assistidos foi o Sul, com cerca de $43 \%$, valor muito superior àqueles obtidos para as demais regiões do País. Tal desproporcionalidade nesses valores é fruto das peculiaridades que determinam o êxito de propriedades familiares rurais da região Sul em suas estratégias de produção e interação com os mercados. Guilhoto et al. (2007) cita que fatores inerentes à forma de colonização e a herança cultural dos povos europeus explicam a motivação de produtores a desenvolverem formas de associativismo, permitindo que pequenas

Quadro 2. Percentual do total dos agricultores familiares assistidos no Brasil em 2014, segundo as fontes prestadoras de serviços de assistência técnica

\begin{tabular}{|l|c|c|c|c|c|}
\hline \multicolumn{1}{|c|}{ Fonte da assistência técnica } & $\begin{array}{c}\text { Empresa de Assistência } \\
\text { Técnica e Extensão } \\
\text { Rural-Emater }\end{array}$ & $\begin{array}{c}\text { Outras agências do } \\
\text { governo (federal, } \\
\text { estadual ou municipal) }\end{array}$ & $\begin{array}{c}\text { Empresa } \\
\text { privada }\end{array}$ & Outra & Total \\
\hline Percentual da população assistida & $41,04 \%$ & $14,78 \%$ & $40,32 \%$ & $3,86 \%$ & $100 \%$ \\
\hline População total de agricultores estimada & 149.399 & 53.804 & 146.778 & 14.051 & 364.033 \\
\hline
\end{tabular}

Fonte: Elaboração própria a partir de dados da PNAD (Instituto Brasileiro de Geografia e Estatística, 2014).

Quadro 3. Percentual de agricultores que receberam assistência, para cada região do País

\begin{tabular}{|l|c|c|c|c|c|c|}
\hline \multicolumn{1}{|c|}{ Região do País } & Norte & Nordeste & Centro-Oeste & Sudeste & Sul & Brasil \\
\hline $\begin{array}{l}\text { Percentual de agricultores familiares } \\
\text { assistidos em cada região }\end{array}$ & $8,56 \%$ & $5,93 \%$ & $11,67 \%$ & $18,43 \%$ & $43,18 \%$ & $16,59 \%$ \\
\hline $\begin{array}{l}\text { População de agricultores total estimada } \\
\text { para cada região }\end{array}$ & 334.286 & 894.774 & 110.674 & 397.097 & 452.974 & 2.189 .805 \\
\hline
\end{tabular}

Fonte: Elaboração própria a partir de dados da PNAD (Instituto Brasileiro de Geografia e Estatística, 2014). ${ }^{3}$ Apresenta a população total estimada de agricultores familiares por região, segundo o recorte amostral utilizado, incluindo aqueles que não receberam assistência técnica. 
unidades produtoras pudessem aumentar seus padrões competitivos. Buainain et al. (2003) expõe que, nas outras regiões, os produtores familiares, de modo geral, aparecem isolados em pequenos grupos em meio à exploração patronal dominante. Esta dispersão dificultou a construção de capital social entre esses agricultores, $\mathrm{o}$ que também impõe restrições ao acesso aos benefícios proporcionados pelos serviços técnicos especializados nestas regiões.

Adicionalmente, também de acordo com Guilhoto et al. (2007), as propriedades familiares das regiões Norte e Nordeste têm características diferentes das do Sul, pois sua existência é derivada de uma agricultura com baixos níveis tecnológicos e de subsistência. O Centro-Oeste, por sua vez, é caracterizado pelo agronegócio de caráter patronal, baseado na grande propriedade e com produção voltada para exportação. Já no Sudeste, destaca-se a relação de fornecimento para indústrias de processamento, distribuição e comercialização dos produtos agropecuários.

No Quadro 4 são apresentados os percentuais de agricultores que utilizaram assistência técnica, segundo a relação do entrevistado com a propriedade.

Os resultados evidenciam que os proprietários dos empreendimentos são os que proporcionalmente recebem mais assistência, seguidos pelos arrendatários. Esses dados indicam que a relação do produtor com a propriedade é um fator que potencialmente interfere no fato de ele ser assistido ou não, tanto que os menores valores percentuais são os de outra condição, cessionário e posseiro, que são condições em que o vínculo com a terra é mínimo, como no caso do posseiro que ocupa e utiliza a terra sem o consentimento do proprietário do terreno, estando, portanto, à margem da lei.

No Quadro 5 são apresentados os percentuais de agricultores familiares que recebem a assistência técnica para cada categoria de principal comprador da produção.

Os dados apresentados no Quadro 5 evidenciam que os produtores que têm como principal comprador o governo, as empresas, ou uma cooperativa, são os que apresentam maior percentual de utilização de assistência técnica. Esse resultado é coerente com o exposto por Batalha et al. (2005), quem indicam que o acesso às tecnologias de produção adequadas está vinculado ao acesso aos canais de comercialização com melhor remuneração. De acordo com o autor, um canal de comercialização que não remunere suficientemente a produção desestimula o investimento em tecnologias, podendo inviabilizar sua adoção. Isso se reflete na

Quadro 4. Percentual de agricultores familiares que receberam assistência técnica segundo a categoria de condição em relação ao empreendimento

\begin{tabular}{|l|c|c|c|c|c|c|}
\hline & Proprietário & Posseiro & Cessionário & Arrendatário & Parceiro & Outra condição \\
\hline $\begin{array}{l}\text { Percentual de agricultores } \\
\text { familiares assistidos }\end{array}$ & $18,20 \%$ & $7,71 \%$ & $6,5 \%$ & $16,03 \%$ & $14,24 \%$ & $4,5 \%$ \\
\hline $\begin{array}{l}\text { População de agricultores } \\
\text { familiares estimada }\end{array}$ & 1.726 .453 & 79.944 & 137.054 & 95.564 & 122.092 & 28.698 \\
\hline
\end{tabular}

Fonte: Elaboração própria a partir de dados da PNAD (Instituto Brasileiro de Geografia e Estatística, 2014). ${ }^{4}$ Apresenta a população total estimada de agricultores familiares para cada categoria de condição em relação ao empreendimento, segundo o recorte amostral utilizado, incluindo aqueles que não receberam assistência técnica.

Quadro 5. Percentual de agricultores que receberam assistência técnica no Brasil em 2014 segundo o principal comprador da produção

\begin{tabular}{|l|c|c|c|c|c|c|c|}
\hline & $\begin{array}{c}\text { Venda } \\
\text { direta ao } \\
\text { consumidor }\end{array}$ & $\begin{array}{c}\text { Venda para } \\
\text { empresa }\end{array}$ & $\begin{array}{c}\text { Venda para } \\
\text { cooperativa }\end{array}$ & $\begin{array}{c}\text { Venda para } \\
\text { governo }\end{array}$ & $\begin{array}{c}\text { Venda para } \\
\text { proprietário }\end{array}$ & $\begin{array}{c}\text { Venda para } \\
\text { intermediário }\end{array}$ & $\begin{array}{c}\text { Outro } \\
\text { comprador }\end{array}$ \\
\hline $\begin{array}{l}\text { Percentual de agricultores } \\
\text { assistidos }\end{array}$ & $5,71 \%$ & $40,38 \%$ & $36,08 \%$ & $41,21 \%$ & $17,46 \%$ & $10,55 \%$ & $11,61 \%$ \\
\hline $\begin{array}{l}\text { População de agricultores } \\
\text { estimada }\end{array}$ & 494.637 & 401.096 & 152.674 & 9.881 & 9.621 & 561.584 & 11.469 \\
\hline
\end{tabular}

Fonte: Elaboração própria a partir de dados da PNAD (Instituto Brasileiro de Geografia e Estatística, 2014). ${ }^{5}$ Apresenta a população total estimada de agricultores familiares para cada categoria de principal comprador da produção, segundo o recorte amostral utilizado, incluindo aqueles que não receberam assistência técnica. A diferença entre a população total deste quadro com os anteriores se deve ao fato de que nem todos os agricultores informaram qual o principal comprador da produção. 
demanda por assistência técnica, uma vez que canais de comercialização menos estáveis (como a venda diretamente para o consumidor) ou com remuneração inferior (como a venda para o proprietário do empreendimento ou para intermediários) estão relacionados aos menores percentuais de agricultores familiares assistidos.

A breve análise descritiva evidencia que as principais fontes de assistência técnica aos agricultores familiares brasileiros são a Emater e as empresas privadas, que respondem por $81 \%$ dos agricultores assistidos. Além disso, verificou-se que os proprietários, arrendatários, e parceiros, proporcionalmente, são as categorias de produtores que mais utilizam o serviço de Ater, embora os percentuais de agricultores familiares atendidos em todas as categorias sejam muito baixos. Com relação ao principal comprador da produção, os agricultores que comercializam para o governo, para empresas privadas, ou para cooperativas, são as categorias com maior percentual de utilização de assistência (em torno de $40 \%$ desses são assistidos), embora representem apenas $32,32 \%$ da população total de agricultores familiares brasileiros. A região Sul também se destacou pelo alto percentual de agricultores que utilizaram o serviço de assistência, contrastando com as demais regiões.

Embora sejam úteis do ponto de vista analítico, esses resultados não permitem isolar o efeito de determinada característica do agricultor com relação à probabilidade de ser assistido, o que limita a realização de inferências sobre o fenômeno. Por esse motivo, visando aprofundar a análise dos dados de modo a contribuir para o entendimento dos determinantes da utilização da Ater pelos produtores, no tópico seguinte apresenta-se o modelo de regressão Probit estimado para esse fim.

\subsection{Análise econométrica}

A consistência da análise econométrica depende fundamentalmente da significância e do ajustamento do modelo estimado. Por esse motivo, antes de proceder à discussão dos resultados, é essencial avaliar o ajustamento do modelo completo estimado. O teste de Wald para a significância global do modelo com todas as variáveis explicativas permitiu a rejeição da hipótese nula a menos de $1 \%$ de significância, o que evidencia que a regressão probit realizada no presente trabalho é estatisticamente significativa. A área sob a Curva Roc, por sua vez, apresentou valor 0,8257 , o que indica, segundo Fávero
\& Belfiore (2014), que o modelo apresenta excelente poder discriminatório.

Outro aspecto a ser considerado é a consistência dos parâmetros estimados, que pode ser avaliada analisando-se a significância e os desvios padrão dos efeitos marginais das variáveis explicativas em modelos com diferentes especificações. Ao incluir variáveis no modelo e comparar com as estimações anteriores é possível avaliar o quão robustas seriam a amostra e as estimações realizadas, verificando se nas diferentes equações seriam observadas mudanças significativas entre os coeficientes estimados. No Quadro 6 são apresentados os resultados de cinco estimações, partindo-se do Modelo 1 , que inclui apenas as variáveis que caracterizam o perfil da pessoa de referência do empreendimento, até o Modelo 5, que inclui todas as variáveis explicativas disponíveis para o presente estudo e é utilizado para a discussão dos resultados. O efeito marginal para todos os modelos foi estimado considerando-se o ponto em que as variáveis contínuas assumem seus respectivos valores médios na amostra, e todas as variáveis dummy assumem valor zero, de modo a viabilizar o cálculo do efeito marginal para uma mudança discreta de 0 para 1 no valor das dummies.

Antes de proceder-se à discussão, é importante ressaltar que, conforme mencionado anteriormente, uma menor probabilidade de utilização da assistência técnica pode resultar tanto da indisponibilidade do serviço para o agricultor quanto da decisão do mesmo em não utilizar o serviço, mesmo quando ele esteja prontamente disponível. Como os dados não permitem a distinção entre um e outro caso, discorre-se sobre ambas as possibilidades, tendo como referência os trabalhos encontrados na literatura sobre o tema.

No Quadro 6 são apresentados os efeitos marginais a partir da estimação de modelos probit.

Na coluna 1 incluiu-se como variáveis explicativas apenas as características da pessoa de referência do domicílio; na coluna 2 foram acrescentadas as variáveis que definem a condição da pessoa de referência com relação à propriedade agrícola; na coluna 3 foram incluídas as variáveis que definem características da atividade produtiva; na coluna 4 foram acrescentadas as variáveis que definem o principal comprador da produção; e na coluna 5, por fim, foram incluídas as variáveis da região de localização do domicílio.

Com base no Quadro 6, percebe-se que, das 24 variáveis incluídas no modelo completo representado 
192 - Análise dos determinantes da utilização de assistência técnica por agricultores familiares do Brasil em 2014

Quadro 6. Estimativa dos efeitos marginais em modelos com aumento progressivo de variáveis explicativas

\begin{tabular}{|c|c|c|c|c|c|}
\hline & Modelo 1 & Modelo 2 & Modelo 3 & Modelo 4 & Modelo 5 \\
\hline Idade & $\begin{array}{c}-0,0005049^{\tilde{n}} \\
(0,00068)\end{array}$ & $\begin{array}{c}-0,0010896^{\tilde{n}} \\
(0,004036)\end{array}$ & $\begin{array}{c}-0,001158^{\tilde{n}} \\
(0,00076)\end{array}$ & $\begin{array}{c}-0,0010255^{\tilde{n}} \\
(0,00065)\end{array}$ & $\begin{array}{c}-0,0021256^{5 \%} \\
(0,00093)\end{array}$ \\
\hline Renda Per Capita & $\begin{array}{c}0,0000448^{1 \%} \\
(0,00001)\end{array}$ & $\begin{array}{c}0,0000447^{1 \%} \\
(0,00001)\end{array}$ & $\begin{array}{c}0,0000492^{1 \%} \\
(0,00001)\end{array}$ & $\begin{array}{c}0,0000281^{1 \%} \\
(0,00001)\end{array}$ & $\begin{array}{c}0,0000373^{1 \%} \\
(0,00001)\end{array}$ \\
\hline Escolaridade & $\begin{array}{c}0,0200312^{1 \%} \\
(0,00237)\end{array}$ & $\begin{array}{c}0,0204324^{1 \%} \\
(0,00243)\end{array}$ & $\begin{array}{c}0,0216082^{1 \%} \\
(0,00258)\end{array}$ & $\begin{array}{c}0,0160086^{1 \%} \\
(0,00246)\end{array}$ & $\begin{array}{c}0,0169647^{1 \%} \\
(0,00316)\end{array}$ \\
\hline Feminino & $\begin{array}{c}-0,0400084^{\text {n }}(0, \\
02861)\end{array}$ & $\begin{array}{c}-0,031346^{\tilde{n}} \\
(0,03065)\end{array}$ & $\begin{array}{c}-0,0349268^{\tilde{n}} \\
(0,03214)\end{array}$ & $\begin{array}{c}-0,0164184^{\tilde{n}} \\
(0,02797)\end{array}$ & $\begin{array}{c}-0,0264658^{\tilde{n}} \\
(0,03873)\end{array}$ \\
\hline Pele não branca & $\begin{array}{c}-0,1507505^{1 \%} \\
(0,01376)\end{array}$ & $\begin{array}{c}-0,1546835^{1 \%} \\
(0,01436)\end{array}$ & $\begin{array}{c}-0,1680373^{1 \%} \\
(0,01549)\end{array}$ & $\begin{array}{c}-0,0977845^{1 \%} \\
(0,01574)\end{array}$ & $\begin{array}{c}-0,0575871^{5 \%} \\
(0,02445)\end{array}$ \\
\hline Cessionário & & $\begin{array}{c}-0,1369402^{1 \%} \\
(0,02947)\end{array}$ & $\begin{array}{c}-0,1442195^{1 \%} \\
(0,0322)\end{array}$ & $\begin{array}{c}-0,1081917^{1 \%} \\
(0,02575)\end{array}$ & $\begin{array}{c}-0,1488665^{1 \%} \\
(0,04194)\end{array}$ \\
\hline Posseiro & & $\begin{array}{c}-0,0500724^{\tilde{n}} \\
(0,04433)\end{array}$ & $\begin{array}{c}-0,0531907^{\bar{n}} \\
(0,04714)\end{array}$ & $\begin{array}{c}-0,006613^{\tilde{n}} \\
(0,04515)\end{array}$ & $\begin{array}{c}0,0350329^{\tilde{n}} \\
(0,06153)\end{array}$ \\
\hline Arrendatário & & $\begin{array}{c}-0,0252406^{\tilde{n}} \\
(0,04208) \\
\end{array}$ & $\begin{array}{c}-0,0157739^{\tilde{n}} \\
(0,0454) \\
\end{array}$ & $\begin{array}{c}-0,0165067^{\tilde{n}} \\
(0,03792)\end{array}$ & $\begin{array}{c}-0,0285139^{n} \\
(0,05382) \\
\end{array}$ \\
\hline Parceiro & & $\begin{array}{c}-0,0393123^{\tilde{n}} \\
(0,0383)\end{array}$ & $\begin{array}{c}-0,0383017^{\tilde{n}} \\
(0,04126)\end{array}$ & $\begin{array}{c}-0,0444989^{\tilde{n}} \\
(0,0319)\end{array}$ & $\begin{array}{c}-0,0676291^{\tilde{n}} \\
(0,04448)\end{array}$ \\
\hline Outra condição & & $\begin{array}{c}-0,1776912^{1 \%} \\
(0,05065) \\
\end{array}$ & $\begin{array}{c}-0,1873239^{1 \%} \\
(0,05632) \\
\end{array}$ & $\begin{array}{c}-0,1366067^{1 \%} \\
(0,04303) \\
\end{array}$ & $\begin{array}{c}-0,1843921^{10 \%} \\
\quad(0,08692) \\
\end{array}$ \\
\hline Produção de subsistência & & & $\begin{array}{c}-0,0332555^{\tilde{n}} \\
(0,02753)\end{array}$ & $\begin{array}{c}-0,0318142^{\tilde{n}} \\
(0,02344)\end{array}$ & $\begin{array}{c}-0,0776601^{5 \%} \\
(0,03304)\end{array}$ \\
\hline Exclusivamente comercial & & & $\begin{array}{c}-0,0705439^{1 \%} \\
(0,01969) \\
\end{array}$ & $\begin{array}{c}-0,0495602^{1 \%} \\
(0,01729) \\
\end{array}$ & $\begin{array}{c}-0,0704296^{1 \%} \\
(0,02396) \\
\end{array}$ \\
\hline Empregado temporário & & & $\begin{array}{c}0,1368924^{5 \%} \\
(0,06508)\end{array}$ & $\begin{array}{c}0,1426942^{5 \%} \\
(0,06412)\end{array}$ & $\begin{array}{c}0,2311745^{1 \%} \\
(0,06574)\end{array}$ \\
\hline Empregado permanente & & & $\begin{array}{c}-0,0522406^{\tilde{n}} \\
(0,05117) \\
\end{array}$ & $\begin{array}{c}-0,0646653^{10 \%} \\
(0,03678) \\
\end{array}$ & $\begin{array}{c}-0,0183491^{\tilde{n}} \\
(0,06056) \\
\end{array}$ \\
\hline Venda direta ao consumidor & & & & $\begin{array}{c}-0,0849328^{1 \%} \\
(0,02264)\end{array}$ & $\begin{array}{c}-0,1012564^{1 \%} \\
(0,03342)\end{array}$ \\
\hline Venda à empresa & & & & $\begin{array}{c}0,2627749^{1 \%} \\
(0,2732) \\
\end{array}$ & $\begin{array}{c}0,2344948^{1 \%} \\
(0,03264) \\
\end{array}$ \\
\hline Venda à cooperativa & & & & $\begin{array}{c}0,1759329^{1 \%} \\
(0,3836)\end{array}$ & $\begin{array}{c}0,1253059^{1 \%} \\
(0,04464)\end{array}$ \\
\hline Venda a proprietário & & & & $\begin{array}{c}0,1311349^{n} \\
(0,1148) \\
\end{array}$ & $\begin{array}{c}0,2026656^{\tilde{n}} \\
(0,13059) \\
\end{array}$ \\
\hline Venda a intermediário & & & & $\begin{array}{r}-0,006162^{\tilde{n}} \\
(0,02351) \\
\end{array}$ & $\begin{array}{c}0,0225222^{\mathrm{n}} \\
(0,03264)\end{array}$ \\
\hline Outro comprador & & & & $\begin{array}{c}-0,0108789^{\tilde{n}} \\
(0,10961) \\
\end{array}$ & $\begin{array}{c}-0,0472647^{\tilde{n}} \\
(0,14917) \\
\end{array}$ \\
\hline Norte & & & & & $\begin{array}{c}-0,2283575^{1 \%} \\
(0,02852)\end{array}$ \\
\hline Nordeste & & & & & $\begin{array}{c}-0,2346783^{1 \%} \\
(0,02951)\end{array}$ \\
\hline Centro-Oeste & & & & & $\begin{array}{c}-0,2531232^{1 \%} \\
(0,03063)\end{array}$ \\
\hline Sudeste & & & & & $\begin{array}{c}-0,1815729^{1 \%} \\
(0,02761)\end{array}$ \\
\hline
\end{tabular}

Fonte: Elaboração própria com base nos modelos estimados. ${ }^{1 \%}$ indica efeito marginal estatisticamente significativo ao nível de $1 \%$ de significância. ${ }^{5 \%}$ indica efeito marginal estatisticamente significativo ao nível de $5 \%$ de significância. ${ }^{10 \%}$ indica efeito marginal estatisticamente significativo ao nível de $10 \%$ de significância. ${ }^{n}$ indica efeito marginal não significativo ao nível de $10 \%$ de significância. Desvio padrão robusto entre parênteses. 
na coluna 5, apenas oito não apresentaram efeito marginal estatisticamente significativo ao nível de 10\% de significância. Essas variáveis foram as dummies para gênero feminino, para posseiro, arrendatário, parceiro ou outra condição em relação ao empreendimento, para participação de empregado permanente no trabalho e as dummies de principal canal de comercialização para a venda direta ao proprietário, venda ao intermediário e para outro comprador.

Outro resultado relevante é que, das 18 variáveis com efeito marginal estatisticamente significativo no modelo completo, 16 também apresentaram efeito significativo em todos os modelos em que foram inseridas. Além disso, considerando um desvio padrão, é possível verificar que não haveria diferença significativa entre os respectivos parâmetros estimados, na maioria dos casos, nos diferentes modelos. Isso evidencia a consistência dos parâmetros estimados no Modelo 5 .

No caso das variáveis que indicam a condição em relação ao empreendimento e o principal comprador da produção, a insignificância de determinada categoria indica que ela é estatisticamente igual à categoria utilizada como base no modelo. Ou seja, estatisticamente, o efeito de o indivíduo ser proprietário do empreendimento no qual trabalha (categoria base), ser posseiro, arrendatário ou parceiro, é o mesmo (não existe diferença significativa entre o efeito dessas categorias sobre a probabilidade de serem assistidos ao nível de 10\% de significância). O mesmo é válido para as categorias de principal comprador da produção, pois os efeitos de o indivíduo vender para o governo (categoria base), para o proprietário, para o intermediário ou para outro comprador são estatisticamente iguais ao nível de $10 \%$ de significância.

Observando a Quadro 6, percebe-se que, tanto para agricultores com idade mais avançada quanto o fato de o indivíduo ter cor da pele não branca, reduzem a probabilidade de utilização de assistência técnica por parte dos agricultores familiares. O efeito da idade tornou-se significativo apenas no modelo completo, após a inserção das dummies de região, o que evidencia a importância de não omitir variáveis importantes no modelo; enquanto que o efeito da cor de pele não branca foi significativo em todas as regressões, evidenciando a consistência do seu respectivo parâmetro estimado. Vale frisar que, para cada modelo, o efeito das demais variáveis incluídas é controlado, implicando que os efeitos de raça e idade resultam exclusivamente de aspectos comportamentais associados a essas características, ou da discriminação no atendimento por parte dos técnicos responsáveis pela Ater.

Pressupõe-se que o último caso não deveria ocorrer, pois seria incoerente com o discurso da nova política da Ater, a qual, segundo Santos \& Doula (2008), pretende assegurar às comunidades rurais o amparo técnico no que diz respeito a ações que focalizam o desenvolvimento sustentável e que não sejam dissociadas de suas especificidades em termos étnicos e culturais. A efetividade deste discurso, na prática, deve ser analisada de forma detalhada, pois é de fundamental importância no sucesso da Ater. Caso não haja discriminação no atendimento aos agricultores, a hipótese mais provável seria, portanto, que existem características comportamentais associadas aos indivíduos com pele não branca, que resultam em menor demanda por assistência técnica por parte dos mesmos, podendo reduzir em até 5,76 p.p. a probabilidade de serem assistidos, o que também exige estudos mais aprofundados para o seu entendimento.

A população de agricultores familiares não brancos estimada no presente trabalho é formada por indivíduos pardos (84,32\% da população, segundo os dados da PNAD de 2014) (Instituto Brasileiro de Geografia e Estatística, 2014), negros (13,93\% da população), indígenas (1,29\%) e amarelos $(0,46 \%)$. É importante considerar que existem programas específicos para enfrentar a desigualdade racial no campo, como o Programa Brasil Quilombola, que foi criado em 2005. Ele é coordenado pela Secretaria Especial de Política de Promoção da Igualdade Racial, e estabelece, segundo Brasil (2005), uma metodologia pautada em um conjunto de ações que possibilitem o desenvolvimento sustentável dos quilombolas em consonância com suas especialidades históricas e contemporâneas, garantindo direitos à titulação e à permanência na terra.

No entanto, apesar da inegável importância desse tipo de programa, é pouco discutido que a maior parcela dos agricultores familiares não brancos é constituída por indivíduos pardos, que representam, segundo o recorte amostral realizado no presente trabalho, uma população estimada em 5,36 milhões de produtores. Sobre essa imensa população de indivíduos pardos, que também são incluídos na categoria não branca, e estão sujeitos ao mesmo efeito identificado no modelo completo apresentado na Quadro 6, de redução na probabilidade de serem assistidos, há poucas informações na literatura sobre Ater, o que evidencia a necessidade 
de sua inclusão nos estudos relacionados à questão dos efeitos da diversidade racial no campo.

O avançar da idade também apresentou efeito de redução na probabilidade de utilização do serviço de assistência técnica. Segundo o modelo 5, apresentado na Quadro 6, um indivíduo com 60 anos de idade, quando comparado a outro com 20, mas com todas as demais características sociais, geográficas e produtivas idênticas, apresenta até 8,5 p.p. a menos de probabilidade de ser assistido. Esse resultado evidencia maior disposição dos jovens em procurar por orientação técnica, consequência de maior disposição pessoal a novos aprendizados e também de projetos direcionados à juventude rural, revelando um aspecto positivo para o desenvolvimento da agricultura familiar.

A redução da probabilidade de utilização de assistência para agricultores com idade mais avançada, por outro lado, pode ser interpretada não apenas como um menor interesse dos agricultores de idade mais elevada em buscar orientação, mas também como o resultado do provável acúmulo de experiência na atividade por parte desses indivíduos, o que reduz a dependência de fontes de conhecimento externas.

Outro resultado relevante é que o fato de o indivíduo não ser cessionário ou apresentar condição não especificada em relação ao empreendimento, de possuir empregados temporários na atividade, ou o aumento da renda per capita aumentam a probabilidade de utilização da assistência técnica. Não foram encontradas referências na literatura específica sobre a Ater, sobre a relação entre as diferentes condições em relação ao empreendimento e a demanda por orientação técnica. No entanto, uma possível explicação para o efeito de redução na utilização de assistência por cessionários ou indivíduos com condição não especificada pode ser o fato de que, em comparação com as demais categorias (arrendatário, proprietário, posseiro e parceiro), esses indivíduos são os únicos que não enfrentam custos diretos pelo uso da terra ${ }^{3}$ (com exceção do custo de oportunidade de seu trabalho), uma vez que os demais, além do custo de oportunidade do trabalho, enfrentam custos financeiros - arrendatário, proprietário e parceiro, que pagam pela terra ou pelo seu uso com dinheiro ou

\footnotetext{
3 Segundo a PNAD (Instituto Brasileiro de Geografia e Estatística, 2014), cessionário é o indivíduo que explorava o empreendimento em bem, móvel ou imóvel, de propriedade de terceiros, com consentimento para usá-lo sem nada pagar.
}

com parte da produção -, ou não financeiros - caso do posseiro, que não tem consentimento de terceiro para o uso da terra e, consequentemente, enfrenta o custo imaterial de ocupar a propriedade.

Em decorrência desse aspecto, os cessionários e os indivíduos com condição não especificada apresentam menor nível de produção mínimo para que atinjam lucro na atividade, o que os torna menos propensos a demandar assistência visando elevar a sua produtividade. O efeito positivo da participação de empregados temporários também pode ser compreendido de maneira semelhante. Indivíduos que utilizam mão de obra de empregados temporários na produção enfrentam maior custo de produção do que os demais. Por esse motivo, para que se atinja um nível de receita que viabilize o lucro, é necessário atingir maiores níveis de produtividade, o que aumenta a demanda por orientação técnica.

O efeito de aumento da probabilidade de utilização de assistência técnica devido ao aumento da renda per capita pode estar associado a diferentes necessidades gerenciais entre propriedades menos rentáveis e mais rentáveis. Segundo o modelo estimado, um aumento de $R \$ 1.000,00$ na renda per capita eleva em 3,73 p.p. a probabilidade de um agricultor utilizar assistência técnica. Batalha et al. (2005), discutindo a questão das tecnologias de gestão na agricultura familiar, ressaltam que essa categoria de produtores enfrenta um conjunto de restrições, sendo que uma das principais é a baixa capacitação gerencial e organizativa. Ainda segundo os autores, o desenvolvimento da atividade de modo sustentado no competitivo mercado agrícola brasileiro demanda ações de capacitação no sentido de orientar não apenas a utilização de tecnologias adequadas de cultivo (o que por si só já é um desafio para essa categoria), mas também a gestão do empreendimento e a articulação com outros agricultores. Pode-se inferir, consequentemente, que propriedades com maior nível de rentabilidade tendem a aproximar-se desse comportamento e, por esse motivo, apresentam maior probabilidade de utilizar o serviço de assistência técnica.

Com base na Quadro 6, identifica-se que a venda direta ao consumidor e a venda para empresas ou para cooperativas apresentam efeito estatisticamente significativo sobre a probabilidade de utilização da assistência técnica. O fato de o indivíduo ter como principal canal de comercialização a venda direta ao consumidor associa-se à uma probabilidade 10,12 p.p. menor de ser assistido 
do que um agricultor com as mesmas características, mas que comercialize para o governo. Por outro lado, as maiores probabilidades associam-se aos que vendem principalmente para cooperativas ou empresas. Os que vendem para cooperativas apresentam 12,53 p.p. a mais, enquanto que os que vendem para empresas apresentam 23,45 p.p. a mais de probabilidade de serem assistidos quando comparados aos que comercializam para o governo.

Esse resultado é coerente, uma vez que, tanto as empresas quanto as cooperativas oferecem serviços privados de assistência técnica aos produtores e ambas têm interesse no aumento da produtividade e da qualidade da produção. Embora os produtores que comercializam para as demais categorias de compradores disponham do serviço público de Ater, a população total de agricultores familiares no Brasil, estimada segundo a amostra utilizada, é de 2.189.805 trabalhadores. Considerando a extensão territorial brasileira e esse imenso contingente de produtores que dependem da Ater pública, pode-se compreender o efeito positivo sobre a utilização de assistência para os agricultores que comercializam para cooperativas e empresas.

Quanto à variável escolaridade, identificou-se que um aumento em cinco anos de estudo implica em avanço de 8,45 p.p. na probabilidade de utilização de assistência técnica pelos produtores familiares. O efeito positivo da escolaridade sobre a probabilidade de utilização da assistência pode ser explicado pelo fato de que os indivíduos mais capacitados tendem a apresentar maior disposição na busca por informação. Essa disposição pode resultar de um maior interesse desses indivíduos por serem inseridos no ambiente de difusão de tecnologias proporcionado pela Ater.

Outro aspecto que apresentou efeito marginal estatisticamente significativo foi a finalidade da produção. Identificou-se que os agricultores que produzem com finalidade exclusivamente comercial ou de subsistência apresentam, respectivamente, 7,04 p.p. e 7,77 p.p. a menos de probabilidade de utilizar a assistência técnica do que aqueles que consomem parte da produção. Esse resultado contraria o que é intuitivamente esperado, porquanto se presumia que aqueles que produzem exclusivamente para a venda demandariam mais assistência técnica devido à especificidade comercial da produção.

Schneider (2003, p. 107), tratando da "[...] teoria da unidade econômica camponesa (UEC) [...]", ressalta que:
[..] a compreensão do funcionamento das unidades econômicas camponesas pressupõe a análise do modo pelo qual as famílias solucionam seus problemas com vistas à manutenção de uma situação de equilíbrio, vital para garantir sua reprodução social. A avaliação subjetiva da família, portanto, é decisiva para definir o "grau de autoexploração" das unidades econômicas camponesas no que se refere ao volume da atividade agrícola, à intensidade do trabalho e ao destino da produção. Tal avaliação tem como referência a manutenção do balanço entre trabalho e consumo (Schneider, 2003, p. 107)

Sob esse ponto de vista, o consumo de parte da produção é uma estratégia de reprodução social adotada pelos agricultores familiares, uma forma de equilibrar consumo e trabalho de modo a otimizar a utilidade de sua produção. Nesse caso, consequentemente, a qualidade de vida da família é ainda mais dependente da qualidade da produção, uma vez que não basta produzir em volume suficiente para comercialização, mas também se almeja um nível de qualidade e uma produtividade que viabilizem também o consumo pela própria família, o que explica a maior utilização da assistência técnica por parte desses indivíduos.

Quanto ao efeito das regiões de localização do empreendimento, identificou-se que, em comparação com a região Sul, todas as demais apresentaram efeito estatisticamente significativo de redução na probabilidade de o agricultor familiar utilizar assistência técnica. Identificou-se redução na probabilidade em 25,31 p.p. para empreendimentos localizados na região Centro-Oeste, 23,47 p.p. para os localizados no Nordeste, 22,84 p.p. na região Norte e 18,16 p.p. no Sudeste. O efeito positivo da região Sul pode ser explicado pela cultura fortemente cooperativista dessa região. Segundo Castro (2015), a proporção de agricultores que aderem ao sistema de cooperativas no Sul é maior do que nas demais regiões brasileiras e, como consequência dessa maior taxa de adesão, as cooperativas na região Sul têm um papel mais relevante em oferecer assistência técnica para seus associados, dispondo de um corpo técnico capacitado para oferecer esse serviço.

Já o efeito da região Sudeste pode ser explicado pelo fato de que esta região, junto ao Sul, foi uma das primeiras do País a contar com o serviço público de Ater. Segundo Oliveira (1999), ao final da década de 1950, os serviços de Ater já estavam presentes na metade dos estados brasileiros, incluindo todos os estados das 
regiões Sudeste e Sul, e expandiam-se para os estados do Nordeste (CE, PE, BA, RN, PB) e Centro-Oeste (GO). $O$ resultado dos efeitos marginais das diferentes regiões são consonantes com essa trajetória espacial da Ater no País, uma vez que estas duas últimas regiões estão associadas às menores probabilidades de utilização de assistência técnica por agricultores familiares no Brasil. Isso evidencia um possível caráter de learning by doing para a Ater, uma vez que a maior tradição no serviço público de assistência correlaciona-se com as maiores probabilidades de utilização do serviço no País.

\section{Conclusão}

Os resultados obtidos evidenciam que a maior parcela de assistência técnica oferecida para agricultores familiares no Brasil é oriunda das agências estaduais da Emater e de empresas. Com os resultados da estimação do modelo probit, comprovou-se a hipótese de que o perfil socioeconômico e as características produtivas e de localização do agricultor familiar afetam a probabilidade de utilização da assistência técnica. Observou-se que o fato de um indivíduo possuir pele não branca, de ter como principal canal de comercialização a venda direta para o consumidor, ser cessionário da terra, possuir idade mais avançada ou baixa escolaridade ou renda per capita apresenta efeito estatisticamente significativo de redução na probabilidade de utilização da assistência técnica. Por outro lado, o fato de o indivíduo ter como principal canal de comercialização a venda para empresas ou para cooperativas, de possuir empregados temporários ou de estar localizado na região Sul aumentam essa probabilidade. Os diferentes efeitos das regiões do País podem ser explicados tanto pelo nível de capital social existente em cada região quanto pela tradição no serviço de Ater, com a região Sul se destacando em ambos os aspectos e podendo servir de benchmark para as demais regiões no processo de estímulo à utilização de orientação técnica por produtores familiares. Conclui-se, por fim, que embora o presente trabalho comprove a existência de efeitos significativos das características mencionadas, são necessários estudos mais aprofundados quanto à origem desses efeitos, que podem estar impactando tanto a oferta da assistência técnica quanto a demanda do mesmo por parte dos agricultores familiares. $\mathrm{O}$ entendimento detalhado desses aspectos é fundamental para que seja construído o respaldo teórico necessário ao constante aperfeiçoamento da Ater no Brasil.

\section{Agradecimentos}

O presente trabalho foi realizado com apoio da Coordenação de Aperfeiçoamento de Pessoal de Nível Superior - Brasil (Capes).

\section{Referências}

Abramovay, R. (1998). Agricultura familiar e desenvolvimento territorial. Reforma Agrária, 28(1), 1-21.

Batalha, M. O., Buainain, A. M., \& Souza Filho, H. M. (2005). Tecnologia de gestão e agricultura familiar. In M. O. Batalha \& H. M. Souza Filho (Org.), Gestão Integrada da Agricultura Familiar (19 p.). São Carlos: EdUFSCar.

Braga, A. C. S. (2000). Curvas ROC: aspectos funcionais e aplicações (Tese de doutorado). Universidade do Minho, Braga.

Brasil. (2004). Ministério do Desenvolvimento Agrário. Secretaria de Agricultura Familiar. Departamento de Assistência Técnica e Extensão Rural. Política Nacional de Assistência Técnica e Extensão Rural. Brasília: MDA.

Brasil. (2005). Ministério do Desenvolvimento Agrário. Secretaria Especial para Políticas de Promoção de Igualdade Racial. Programa Brasil Quilombola. Brasília: Ministério do Desenvolvimento Agrário.

Brasil. (2006, julho 24). Lei ${ }^{\circ} 11.326$, de 24 de julho de 2006. Estabelece as diretrizes para a formulação da Política Nacional da Agricultura Familiar e Empreendimentos Familiares Rurais. Diário Oficial [da] República Federativa do Brasil, Brasília. 7 p.

Brasil. (2008). Ministério do Desenvolvimento Agrário. Secretaria de Agricultura Familiar. Departamento de Assistência Técnica e Extensão Rural. Política Nacional de Assistência Técnica e Extensão Rural. Brasília: Ministério do Desenvolvimento Agrário.

Brasil. (2017, maio 31). Decreto no 9.064, de 31 de maio de 2017. Dispõe sobre a Unidade Familiar de Produção Agrária, institui o Cadastro Nacional da Agricultura Familiar e regulamenta a Lei no 11.326 , de 24 de julho de 2006, que estabelece as diretrizes para a formulação da Política Nacional da Agricultura Familiar e empreendimentos familiares rurais. Diário Oficial [da] República Federativa do Brasil, Brasília. 
Buainain, A. M., Romeiro, A. R., \& Guanziroli, C. (2003). Agricultura familiar e o novo mundo rural. Sociologias, 5(10), 312-347.

Cameron, A. C., \& Trivedi, P. K. (2010). Microeconometrics using stata. College Station: Stata Press.

Caporal, F. R. (1998). La extensión agraria del sector público ante los desafíos del desarrollo sostenible: el caso de Rio Grande do Sul, Brasil (Tese de doutorado). Programa de Doctorado en Agroecología, Campesinado e Historia, Universidad de Córdoba, Córdoba.

Castro, C. N. (2015). Desafios da agricultura familiar: o caso da assistência técnica e extensão rural (Boletim Regional, Urbano e Ambiental, No. 12, pp. 49-59). Brasília: IPEA.

Centro de Estudos Avançados em Economia Aplicada - CEPEA. (2016). Relatório PIB do Agronegócio-Brasil. Recuperado em 13 de maio de 2017, de http:/ / www. cepea.esalq.usp.br/upload/kceditor/files / Relatorio $\% 20$ PIBAGRO\%20Brasil_DEZEMBRO.pdf

Fávero, L. P., \& Belfiore, P. (2014). Métodos quantitativos com Stata (248 p.). Rio de Janeiro: Elsevier.

Guilhoto, J. J., Ichihara, S. M., Silveira, F. G. D., Diniz, B. P. C., Azzoni, C. R., \& Moreira, G. R. (2007). A importância da agricultura familiar no Brasil e em seus estados. Brasília: NEAD. Recuperado em 1 de fevereiro de 2017, de https://www.researchgate.net/profile/ Carlos_Azzoni/publication/4731981_A_IMPORTANCIA DA_AGGICULTURA_FAMILIAR_N̄-_BRASIL_E_EM SEŪS_ESTADOS/links / Offfd5089e9a $\overline{9}$ ec637000000.pdf

Gujarati, D. N., \& Porter, D. C. (2011). Econometria básica (5a ed., 846 p.). Porto Alegre: Editora AMGH.

Instituto Brasileiro de Geografia e Estatística - IBGE. (2009). Censo Agropecuário 2006. Rio de Janeiro: IBGE.

Instituto Brasileiro de Geografia e Estatística - IBGE. (2014). Pesquisa Nacional por Amostra de Domicílios 2014: notas metodológicas, pesquisa básica e pesquisas suplementares de acesso à internet e à televisão e posse de telefone móvel celular para uso pessoal, acesso ao cadastro único para programas sociais do governo federal, acesso a programas de inclusão produtiva, e mobilidade socio-ocupacional (97 p.). Brasília: IBGE.
Landau, E. C., Cruz, R. K., Hirsch, A., Pimenta, F. M., \& Guimarães, D. P. (2012). Variação geográfica do tamanho dos módulos fiscais no Brasil (199 p.). Sete Lagoas: Embrapa Milho e Sorgo.

Oliveira, M. M. (1999). As circunstâncias da criação da extensão rural no Brasil. Cadernos de Ciência \& Tecnologia, 16(2), 97-134.

Portal Atividade Rural. (2013). Manual de crédito rural 2013/2014. Recuperado em 20 de novembro de 2016, de http:/ / atividaderural.com.br/artigos/51db43efe657c.pdf

Peixoto, M. (2009). A extensão privada e a privatização da extensão: uma análise da indústria de defensivos agrícolas. (Tese de doutorado). Universidade Federal Rural do Rio de Janeiro, Rio de Janeiro.

Quirino, T. R., Garagorry, F. L., \& Sousa, C. P. (2002). Diagnóstico sociotécnico da agropecuária brasileira: I. produtores (Documentos, 58 p.). Brasília: Embrapa, Secretaria de Administração Estratégica.

Rivera, W. M., \& Cary, J. W. (1997). Privatizing agricultural extension. In B. E. Swanson, R. P. Bentz \& A. J. Sofranko (Orgs.), Improving agricultural extension - a reference manual (pp. 297-311). Rome: FAO. Recuperado em 17 de junho de 2017, de http:/ / www.fao.org/docrep/w5830e/ w5830e00.htm\#Contents\#Contents

Santos, A., \& Doula, S. M. (2008). Políticas públicas e quilombolas: questões para debate e desafios à prática extensionista. Revista Extensão Rural, 15(16), 67-83.

Schneider, S. (2003). Teoria social, agricultura familiar e pluriatividade. Revista Brasileira de Ciências Sociais, 18(51), 99-121.

Teixeira, E. C. (2002). O papel das políticas públicas no desenvolvimento local e na transformação da realidade (11 p.). Salvador: AATR. Recuperado em 2 de fevereiro de 2017, de http:/ / www.dhnet.org.br/dados/cursos / aatr2/a_pdf/03_aatr_pp_papel.pdf

Wanderley, M. N. B. (2013). Agricultura familiar e campesinato: rupturas e continuidade. Estudos Sociedade e Agricultura, 1, 42-61. 